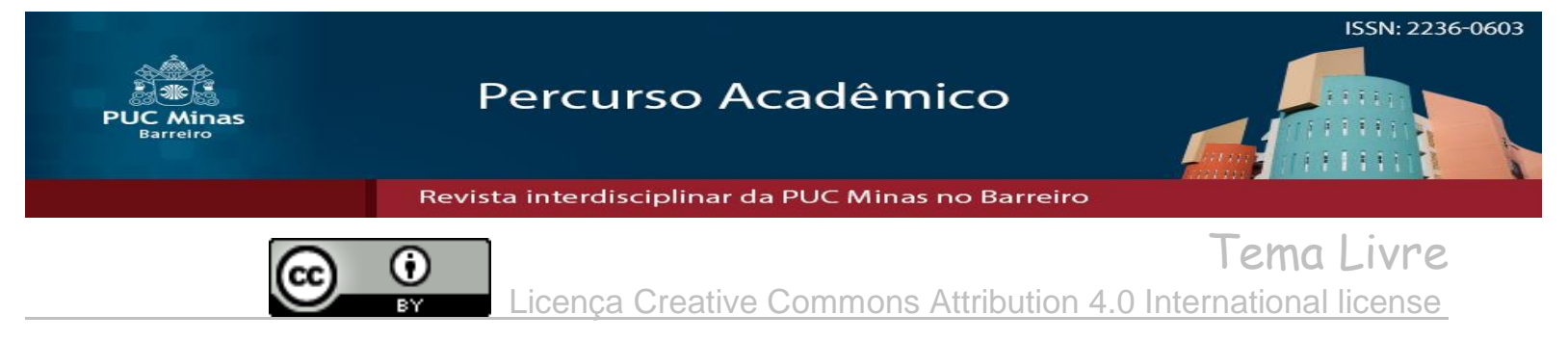

\title{
Estimação dos custos de importação para uma empresa do ramo de plásticos: análise do impacto no custo do produto vendido
}

\author{
Bruno Henrique Ferreira de Paulino ${ }^{1}$ \\ Josmária Lima Ribeiro de Oliveira ${ }^{2}$ \\ Ana Tereza Lanna Figueiredo ${ }^{3}$
}

\begin{abstract}
RESUMO
O objetivo do artigo consiste em analisar o impacto da substituição de matéria-prima nacional por similares importados, considerando o Custo do Produto Vendido, a partir da operacionalização do processo de importação. $\mathrm{O}$ estudo de caso foi aplicado a uma indústria paulista que fornece compostos plásticos, principalmente para injeção na indústria automotiva. A matéria-prima básica utilizada é o polímero polipropileno, produto que no Brasil é vendido exclusivamente pela empresa Braskem. A representatividade do produto nos custos de produção é relevante, assumindo $60 \%$ dos custos e das despesas da empresa. A monopolização da venda do produto direciona a análise para a importação, a fimm de se ter uma análise comparativa quanto ao dispêndio financeiro. A metodologia de estudo de caso contou com a coleta de dados de informações fiscais, financeiras e contábeis via questionário, entrevista semiestruturada e pesquisa documental. Os resultados demonstram que a importação é uma decisão acertada para a indústria, uma vez que a mesma terá redução dos custos e melhoria do seu ciclo financeiro por reduzir a necessidade de capital de giro. Apesar de tal cenário sofrer impacto da variação cambial, percebe-se que a estrutura de mercado monopolista, com adoção de preços e prazos restritos, frente às políticas de incentivo à comercialização com o Mercosul, tornaram atrativas as importações diante da análise comparada.
\end{abstract}

Palavras-chave: Polipropileno, Estimação de custos, Importação, Custo do produto vendido.

\footnotetext{
Artigo recebido em 08 de dezembro de 2018 e aprovado em 14 de fevereiro de 2020

${ }^{1}$ Graduando em Ciências Contábeis na Pontifícia Universidade Católica de Minas Gerais (PUC MG), Brasil.

2 Doutora em Ciência da Informação, mestre em Administração com ênfase em agronegócio, especialização em administração de sistemas de informação, graduação em Ciências Contábeis e Administração. Atualmente é Assistente IV da PUC MG, Brasil. E-mail: josmaria@ pucminas.br

${ }^{3}$ Doutora e Mestre em Economia pelo CEDEPLAR da Universidade Federal de Minas Gerais (UFMG). Atualmente é Professora Adjunto III da Pontifícia Universidade Católica de Minas Gerais, Brasil. E-mail: anaterezalanna@gmail.com
} 


\section{INTRODUÇÃO}

O Brasil tem passado por transformações significativas em relação à política externa, com adoção de um maior protecionismo, vivenciando um maior isolamento do mercado nacional com a implantação de inúmeras barreiras alfandegárias em certos setores e políticas de incentivos. Essas práticas levaram o país a ser denunciado na OMC - Organização Mundial do Comercio e receber a maior condenação de sua história em 2017 (AGÊNCIA BRASIL, 2017). A abordagem de tal temática e o estudo de casos tende a favorecer a visibilidade do cenário brasileiro quanto à política externa, lançando luz sobre as barreiras alfandegárias que afetam o mercado nacional.

O Brasil é ainda altamente dependente do mercado externo em relação a produtos que envolvem um grau maior de tecnologia (FURTADO, 2011). Apesar de a balança comercial brasileira ser favorável de forma geral, o país depende das economias desenvolvidas para aquisição de eletrônicos, medicamentos, compostos químicos, entre outros, produtos esses que por falta de infraestrutura, em termos de maquinários, insumos e mão de obra qualificada são impossíveis de serem produzidos no país. Sob essa ótica, importar é uma questão vital para a sustentação do mercado nacional e bemestar geral da população. A moeda brasileira vive à deriva das oscilações no mercado externo e interno, e a gestão de custos no processo de importação é fundamental para as empresas se manterem competitivas no mercado.

A dependência tecnológica e o protecionismo direcionam ao nascimento de monopólios com questões polêmicas no mercado de polipropileno, um tipo de termoplástico. O objetivo do artigo consiste em levantar, a partir do processo de Custo do Produto Vendido (CPV), um estudo de caso aplicado a indústria do setor de compostos plásticos para o ramo automobilístico, o custo de oportunidade que a importação pode gerar, em relação aos custos da compra nacional. A metodologia adotada foi o estudo de caso, aplicado em uma empresa produtora de compostos plásticos para indústrias transformadoras do produto. $\mathrm{O}$ foco serão os itens produzidos tendo como base a resina de PP (polipropileno). O principal mercado do PP são as montadoras que utilizam o produto para injeção de peças plásticas.

A empresa em análise está situada no estado de São Paulo e atua no mercado desde 1977, tendo sido vendida diversas vezes. O mercado automotivo é altamente sensível a variações no PIB, sendo a demanda altamente afetada em momentos de crise. O mesmo acontece com toda a cadeia produtiva envolvida nesse setor. No caso da 
empresa, os custos do produto representam um percentual altíssimo da receita líquida, e o ciclo financeiro é positivo e grande. Em tal cenário a empresa está em constante necessidade de capital de giro, tendo saldo em tesouraria em geral negativo. A realidade não é exclusiva da empresa investigada neste estudo de caso, pois se aplica às empresas que fornecem para as grandes montadoras. Tais empresas não possuem poder de negociação e são forçadas a ceder prazos de pagamento, que geralmente superam 60 dias.

Diante de tal cenário desfavorável as empresas precisam definir estratégias para garantir a continuidade operacional e estratégica. Entre as possibilidades de ajuste, temse a apropriação dos processos de compra internacional para comparar resultados com mercado nacional. Em alguns casos, a empresa pode adotar a redução dos custos, mas piorar seu ciclo financeiro aumentando as despesas financeiras. Contudo, caso o resultado seja favorável para a redução dos custos e para a redução da necessidade de capital de giro, a importação pode ser vista como uma decisão favorável ao negócio.

Para a estruturação do trabalho, considerou-se uma discussão inicial sobre o mercado de polipropileno no Brasil, focando no antes e depois da monopolização do mesmo, pela empresa Braskem S/A. Nesta seção são abordadas questões relativas a decisões controversas do CADE - Conselho Administrativo de Defesa Econômica. E, em seguida, apresenta-se a construção da abordagem sobre as compras internacionais diante da linha de pesquisa adotada. Na seção da metodologia de estudo é apresentada a técnica de coleta de dados utilizada para o desenvolvimento de estudo de caso, assim como os recursos metodológicos adotados para a análise dos dados. E finalmente apresenta-se a análise comparada de três experiências de compra internacional aferindo os resultados financeiros obtidos.

\section{O MERCADO DE POLIPROPILENO NO BRASIL}

De acordo com Carvalho e Toledo (2000) o mercado de polipropileno no Brasil ganhou desenvoltura a partir da década de 1990, com ampliação da capacidade instalada das fábricas já existentes e instalação de novas plantas produtoras de termoplásticos. $\mathrm{O}$ autor analisou a situação do mercado, sendo o estudo mais completo realizado para o produto no Brasil. Na época, antes de o mercado ser monopolizado, havia diversas empresas produtoras concorrendo entre si, o que beneficiava as empresas consumidoras 
Bruno Henrique Ferreira de Paulino, Josmária Lima Ribeiro de Oliveira e

Ana Tereza Lanna Figueiredo

e contribuía para manter os preços mais baixos. Conforme Tabela 1, existiam 3 principais empresas no mercado, sendo a PoliBrasil a com maior capacidade instalada.

Tabela 1: Principais produtoras de PP em 2000

\begin{tabular}{|l|c|c|c|}
\hline Empresa & Unidade & Capacidade 1999 & Capacidade 2001 \\
\hline Ipiranga & Triunfo (RS) & 150.000 ton/ano & 150.000 ton/ano \\
\hline \multirow{2}{*}{ OPP } & Triunfo (RS) & 550.000 ton/ano & 550.000 ton/ano \\
\cline { 2 - 4 } & Camaçari (BA) & 125.000 ton/ano & 125.000 ton/ano \\
\cline { 2 - 4 } & Duque de Caxias (RJ) & 180.000 ton/ano & 250.000 ton/ano \\
\cline { 2 - 4 } & Mauá (SP) & 125.000 ton/ano & 300.000 ton/ano \\
\hline TOTAL & - & 1.130 .000 ton/ano & 1.375 .000 ton/ano \\
\hline
\end{tabular}

Extraído de: Carvalho e Toledo (2000).

O trabalho realizado por Carvalho e Toledo (2000), foi voltado às propriedades químicas do produto e possivelmente desenvolvimento de novas tecnologias, o que tornaria o PP um substituto para outros polímeros. Dada essa característica do trabalho, o autor não discorreu de forma mais aprofundada sobre as condições de mercado, mas o legado ainda sim é essencial para podermos traçar um comparativo 18 anos depois de sua publicação. Os dados demonstram que em 2000, a OPP, que no futuro através de diversas aquisições e fusões se tornaria a atual Braskem S/A já era a segunda principal empresa no mercado, tendo sido fundada em 1995, pelo grupo Odebrecht.

Petry (2011) vislumbrava o potencial de mercado e desenvolveu uma investigação específica sobre a situação do mercado e as utilizações, fazendo as projeções para a expansão do mesmo, especialmente por seu valor para o Setor Automobilístico. Petry (2011) justifica que o polímero, além de permitir maior flexibilidade em projetos também permite economia no processo produtivo.

A Braskem S/A nasceu em 2002 com a integração das empresas: Copene, OPP, Trikem, Proppet, Nitrocarbono, e Polialden. Tal integração a tornou a maior empresa petroquímica da América Latina. Apesar da concentração, ainda havia concorrência no mercado tendo empresas independentes como a Ipiranga. Em 2005, Braskem e Petrobras firmam parceria para construção de uma planta de produção de PP em Paulínia, um fato muito importante que levaria a configuração do mercado da forma como se encontra hoje, já que a Odebrecht e Petrobras são as principais controladoras da empresa Braskem. 
Estimação dos custos de importação para uma empresa do ramo de plásticos:

análise do impacto no custo do produto vendido

Barrionuevo Filho e Lucinda (2006) estudaram os efeitos da integração da Copene pelo grupo Odebrecht S/A, controlador da Braskem, no mercado de polímeros, "partindo das características da indústria, foi utilizado o Modelo de Cournot para a obtenção de estimativas dos efeitos sobre preço, quantidade e concentração de mercado" (BARRIONUEVO FILHO e LUCINDA, 2006, p. 8). Com o estudo os autores demonstraram os futuros efeitos negativos dessa operação por meio de estimações econométricas.

As principais conclusões destas simulações, partindo da formação da empresa BRASKEM e consequente controle da maior parcela da produção de eteno no Brasil e do aumento da concentração da capacidade produtiva no setor de polietilenos, foram:

1. Elevação do preço médio dos polietilenos no mercado brasileiro;

2. Redução da quantidade total de polietilenos consumida;

3. Elevação da concentração no setor, medida pelo Índice Herfindahl-Hirschmann;

4. Maior participação de mercado da empresa BRASKEM, o que reforça sua posição dominante.

Os fundamentos de teoria econômica que sustentam estes resultados são de que uma fusão que provoca aumento de concentração sem gerar sinergias significativas, que poderiam reduzir custos marginais, em um oligopólio do tipo Cournot, gera maior concentração, portanto, maiores margens de lucro e maiores preços aos consumidores (grifo nosso), (BARRIONUEVO FILHO; LUCINDA, 2006, p. 16).

O ano de 2007 foi o passo que marcou a monopolização do mercado de PP onde a Braskem, junto com a Petrobras e a Ultrapar adquiriram o grupo Ipiranga, repartindo as operações da empresa adquirida entre si, ficando a Braskem com o controle da Ipiranga Petroquímica. A operação foi altamente controversa, com acusação de vazamento das negociações junto a CVM e também ao CADE, já que o mesmo o reconheceu, por unanimidade, a preservação da competitividade nos mercados envolvidos na operação.

A consolidação do mercado de PP foi finalizada em 2010, com a aquisição da petroquímica Quattor pela Braskem, também com aprovação por unanimidade do CADE, o que nas palavras do jornal Soares e Araújo (2010) "nasce um monopólio na produção de petroquímicos básicos no país". O CADE impôs restrição em cláusulas de 
exclusividade de importação de resina, mas isso não seria problema para a empresa já que a Camex - Câmara de Comércio Exterior, assumiria a tarefa asseguração do monopólio com a imposição de tarifas de direito antidumping para proteger $\mathrm{o}$ monopólio de qualquer concorrência.

Em termos de produção, a América Latina não ocupa posição de destaque no mercado de polipropileno demonstrado no gráfico a seguir com dados do ano de 2016. Os maiores produtores se encontram na Ásia, seguidos da Europa e América do Norte, mercados estes que poderiam ser potenciais alternativas para fugir do monopólio do produto no país, já que a China apesar de ser o maior produtor também é o maior consumidor do produto no mundo. Entretanto, além do Imposto de Importação incidente sob a mercadoria importada e as outras taxas, a Camex impôs diferentes alíquotas incidentes sob valor importado a título de direitos antidumping.

\section{Figura 1: Produção global de polipropileno em 2016.}

Global Production of Polypropylene
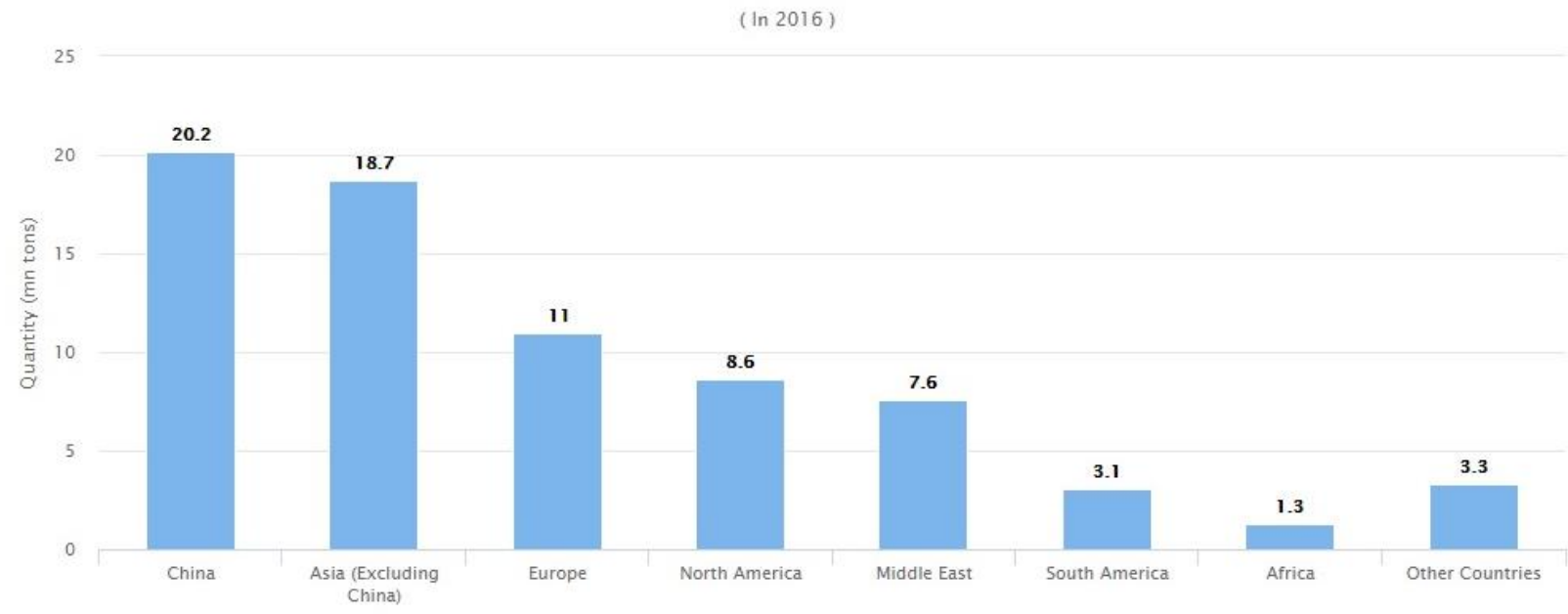

Extraído de: Plastics Insights (2016).

Como exemplo, cita-se a resolução Camex 104 de 01/11/2016 que impõe direito de aplicação de alíquota ad valorem de $10,6 \%$ sobre produtos classificados no NCM 3902.30.00, que é o utilizado na classificação do PP no país, para importações oriundas dos Estados Unidos. Diversas outras resoluções recaem sobre a importação do produto, com tarifas chegando a 16\% para PP importado da África do Sul. A Camex inclui também a necessidade de licença de importação - LI para esse NCM. 
Estimação dos custos de importação para uma empresa do ramo de plásticos:

análise do impacto no custo do produto vendido

Esse cenário coloca as empresas brasileiras em uma situação de impotência perante o mercado dominado pela Braskem. Entretanto, há uma alternativa de importação, que seria encontrar fornecedores dentro do bloco Mercosul. Baseado nesse acordo de comércio, com os países do bloco, será desenvolvida uma estimação de custos para importação de PP pela prospecção de um fornecedor dentro do bloco e posterior comparação com os preços praticados pelo fornecedor nacional para verificar os efeitos sobre o custo da matéria-prima.

\section{ESTIMAÇÃO DE CUSTOS NA IMPORTAÇÃO}

A temática de compras internacionais alinhadas ao processo de estimação de custos, registram estudos de caso em setores distintos, como foi o caso da varejista de componentes eletrônicos (OLIVEIRA, SOUZA e OLIVEIRA, 2005), de um laboratório veterinário (OLIVEIRA, PACHECO e OLIVEIRA (2006), de uma siderúrgica (OLIVEIRA, SOUZA e RIBEIRO, 2007), da empresa de materiais refratários (OLIVEIRA et al, 2008a), e da indústria automobilística (OLIVEIRA et al, 2008b). Pela análise de casos múltiplos foi possível estruturar um instrumento de coleta de dados quantitativo que foi validado por 123 empresas do estado de Minas Gerais (OLIVEIRA e RIBEIRO, 2008). Entretanto, com o avanço dos sistemas de informação e da integração na cadeia de suprimentos as análises pela abordagem qualitativa demonstram ser uma abordagem relevante ao se considerar a continuidade e atualização dos estudos e das descobertas encontradas.

E, Amaral et al (2019) apropriaram dos embasamentos da linha de estudos para aplicar a análise da estimação de custos de logísticos para a importação em empresas de pequeno e médio porte, hoje mais acessíveis a tecnologia e aos trâmites alfandegários, após as alterações de algumas práticas governamentais quanto ao controle adotado. Já Franco, Bernardo e Oliveira (2019) consideraram uma análise processual em uma organização de pequeno porte que necessita dos insumos importados para permanecer competitiva no mercado, e pelo estudo realizado, conseguiram demonstrar os atuais desafios da importação para a melhoria das margens de lucro, além do controle do ciclo financeiro para a organização.

$\mathrm{Na}$ revisão de literatura não foi encontrado outro estudo de estimação de custos de importação voltado especificamente para o mercado de prolipropileno, mas há vários 
estudos de casos disponíveis que contribuem para uma melhor condução desse trabalho. O que justifica observar este mercado e compreender as características que o identificam. Contudo, chama atenção o trabalho de Ben e Aimi (2017), que considerou a análise de custos para a aquisição de matéria-prima em uma indústria de plásticos, no Sul do Brasil. O estudo de caso permitiu a análise comparativa entre os custos de produto nacional e importado. Os resultados afirmaram que a importação registra vantagem econômica para a indústria de plásticos, quando comparada com a mesma compra no mercado interno. O novo fornecimento favoreceu pela análise dos resultados, uma redução significativa dos custos para a empresa em análise.

Segundo Oliveira et al (2005) para a tomada de decisão quanto à importação, o envolvido na decisão de importação precisa ter profundo conhecimento sobre o produto, no que tange às especificações dos mesmos. Oliveira et al (2008a) estudaram o processo comercial de importação com a aplicação do estudo de caso explanatório (casual), em uma empresa que fabrica refratários para altos fornos, situada em Contagem/MG. O objetivo do estudo compreendeu identificar os componentes logísticos que envolvem o processo de compra de produtos importados. A metodologia utilizada foi exploratória e o instrumento de pesquisa utilizado foi um questionário semiestruturado aplicado através de uma entrevista com o gerente de compras. As principais evidências encontradas no estudo foram que o processo de estimação de custos varia de acordo com o INCOTERM utilizado e o tempo de entrega necessário, além das propriedades da proposta de compra. Pelo estudo de caso, os autores identificaram que a empresa em questão apresenta um processo de estimação dos custos de importação padronizado. Entretanto, a documentação da rotina pela equipe de qualidade não é acessível a todos, o que foi um fator a ser aprimorado para o processo de governança das compras internacionais.

Ao investigar a indústria automobilística, Oliveira et al (2008b) descreveram a atividade de importação e sua estimação de custos. Como no artigo anterior o problema central do estudo foi analisar os estágios do processo de estimação dos custos de importação através da análise do processo de compras. As entrevistas semiestruturadas direcionadas ao departamento de compras da empresa permitiram identificar que a estimação dos custos é feita por meio de uma planilha eletrônica onde são elencados todos os custos estimados. Entre os resultados encontrados, os autores identificaram que a confiabilidade do fornecedor é um fator relevante para o processo de decisão da 
Estimação dos custos de importação para uma empresa do ramo de plásticos:

análise do impacto no custo do produto vendido

compra, assim como o preço. Dada a natureza do setor automobilístico, a confiabilidade destacou-se como fator intrínseco, o que diferencia esse estudo de caso do anterior.

Os trabalhos citados demonstram que a estrutura do processo de estimação dos custos de importação remete a uma estrutura similar, variando quanto às particularidades de cada mercado, e quanto às estratégias logísticas e financeiras adotadas. $\mathrm{O}$ envolvimento do departamento de compras, como um todo, será um ponto de divergência desse estudo já que todo o processo é centralizado no supervisor de planejamento de produção e não no departamento de compras, como encontrado na maioria dos trabalhos revisados. Uma hipótese para explicar essa particularidade na empresa proposta para esta investigação é o porte em número de funcionários, por ser classificada como pequena, apesar de o faturamento a colocar como empresa de médio porte. Um aditivo à linha de pesquisa consiste na análise de impacto do ciclo operacional e financeiro.

\section{METODOLOGIA}

A metodologia adotada consistiu em um estudo de caso descritivo e aplicado a uma indústria paulista, que fornece compostos plásticos, principalmente para injeção na indústria automotiva. Pela análise da situação vivenciada, foi possível identificar percepções quanto ao mercado e mapear as estratégias para contornar os problemas característicos do ramo automotivo.

O primeiro contato com a empresa foi por meio de um questionário estruturado, a fim de identificar elementos centrais para construção de um segundo questionário, mais amplo. Nesta etapa, o entrevistado foi um profissional da área de compras que também realizar compras internacionais. A segunda abordagem focou a busca de informações específicas sobre a estrutura de custos, a prática de estoques da empresa, as políticas de vendas, o perfil dos clientes e o perfil dos fornecedores. Mas, principalmente, sobre o processo de importação de produtos e as variáveis envolvidas na operação, que subsidiavam a decisão sobre a compra internacional.

Desse segundo questionário foi elaborado um roteiro de entrevista semiestruturada, realizada com o responsável por coordenar as importações na empresa, e também por tomar a decisão quanto à compra no mercado local ou internacional. $\mathrm{O}$ roteiro foi construído de forma a garantir que a entrevista durasse cerca de uma hora e abordasse todos os assuntos citados no questionário semiaberto. A ideia era fazer com 
que o entrevistado, que no caso da empresa ocupa o cargo de supervisor de PCP, descrevesse as operações da empresa e todas as variáveis que impactavam nas decisões estratégicas, focando na estimação dos custos de importação.

O trabalho contou também com uma análise documental. A empresa disponibilizou sua planilha de custos, as notas fiscais, as cotações de fornecedores internacionais, a tabela de preço dos fornecedores, e a planilha utilizada para estimação de custos de importação. Entre os documentos, foi possível acessar algumas planilhas de custos de importações efetivamente realizados, ou seja, preenchidas.

Como o enfoque era o mercado de polipropileno foi necessário selecionar quais itens seriam utilizados no estudo de caso, já que a empresa utilizava dezenas de itens à base de polímero de polipropileno. Para resolver essa questão foi utilizada a planilha disponibilizada com o CPV da empresa, que continha dados de janeiro a setembro de 2018. Os dados apresentados geraram um CPV médio do período. E, os itens foram elencados em ordem decrescente, em termos de custo. Após tal organização, foi calculado o percentual de participação de cada um no custo total.

$\mathrm{Na}$ segunda etapa, foram selecionados os 20 itens com maior percentual de participação, sendo encontradas as resinas. Em seguida, foram eliminados os itens que atualmente são importados por não terem similares nacionais, como foi o caso dos polímeros de polipropileno ABS. Tais polímeros são resinas de baixo brilho, e basicamente são produzidas por um único fornecedor no mundo. Toda essa etapa contou com a ajuda do supervisor de PCP. Dos itens que sobraram, foi sugerido pelo supervisor, que o trabalho focasse nos três itens mais consumidos no processo produtivo da empresa, os quais foram escolhidos para a descrição na seção a seguir.

Para a análise dos dados, utilizou-se a triangulação das fontes de informação, orientada pela análise de conteúdo categorial. O roteiro da investigação, assim como o quadro conceitual para as rubricas analisadas, compreendeu a base de referência da pesquisa de Oliveira e Ribeiro (2008). Pela abordagem descritiva, foi possível iniciar a construção das análises a partir de uma descrição grossa que foi refinada e aprimorada diante da confrontação das fontes de informação e interações com a organização e suas fontes documentais. 


\section{ANÁLISE E RESULTADOS}

\subsection{Análise do ciclo operacional e financeiro da empresa}

Para a estimação dos custos de importação, considerando a análise de viabilidade é importante realizar uma análise do ciclo operacional e financeiro da empresa. Essa questão é relevante porque cerca de $60 \%$ dos custos e despesas totais da empresa são com compras de polipropileno, que por sua vez são provenientes de um único fornecedor, devido à característica de monopólio do mercado.

Os indicadores de ciclo operacional e ciclo financeiro são importantes porque vão demonstrar até que ponto esse fato impacta a empresa. No setor automotivo, as montadoras se financiam com seus fornecedores, ao se beneficiar dos longos prazos de pagamentos, se valendo do alto poder de negociação. Esses dois fatos parecem criar um cenário extremamente negativo para a sobrevivência da empresa, que é fornecedora de uma indústria automotiva. Segundo Assaf Neto e Silva (2011) o ciclo operacional representa as operações presentes no processo produtivo se iniciando com a aquisição da matéria-prima e finalizando na venda do produto final. Já o "ciclo financeiro mede exclusivamente as movimentações de caixa, abrangendo o período compreendido entre o desembolso inicial de caixa (pagamento de materiais a fornecedores) e o recebimento da venda do produto" (ASSAF NETO; SILVA, 2011, p. 12).

Pela coleta de dados, foi possível obter todas as informações necessárias para construir os ciclos, que envolvem dados do Balanço Patrimonial e Demonstração de Resultado do Exercício da empresa, no ano de 2018. De acordo com Padoveze e Benedicto (2010) o ciclo operacional é dado pela soma do prazo médio de recebimento ao prazo médio de estocagem. E, de acordo com Assaf Neto e Silva (2011) o ciclo financeiro é calculado a partir da resultante ciclo operacional subtraída do prazo médio de pagamento. Com base nos dados obtidos, o prazo médio de recebimento é de 65 dias, o prazo médio de estocagem é de 30 dias, e o prazo médio de pagamento é de 5 dias, já que as compras de polipropileno são pagas de forma antecipada à Braskem. A empresa possui um limite de crédito aprovado junto ao fornecedor, porém o mesmo é irrisório perto do volume de compras que realiza, e a representatividade do fornecedor frente ao consumo de matéria prima. Essas informações apontam um ciclo operacional de 95 dias e um ciclo financeiro de 90 dias. Quanto mais longo o ciclo financeiro, maior é a necessidade de capital de giro da empresa. 


\section{Bruno Henrique Ferreira de Paulino, Josmária Lima Ribeiro de Oliveira e}

\section{Ana Tereza Lanna Figueiredo}

Essa já era a situação esperada pela análise preliminar dos dados, que apenas corrobora a informação citada de que a empresa não tem poder de negociação frente aos clientes - as montadoras. E, nem poder de negociação frente ao fornecedor de matériaprima básica, por ser o único no mercado. A seguir será estudada a importação como alternativa ao monopólio do mercado nacional e seu impacto para com o ciclo financeiro da indústria.

\subsection{Estimação dos custos de importação}

Para o estudo de viabilidade da importação em comparação aos custos da compra nacional, foram selecionados com base no CPV. Após tratamento dos dados chega-se aos três tipos de polímeros de polipropileno listados na Tabela 2, com suas respectivas participações no $\mathrm{CPV}$.

\begin{tabular}{lc}
$\begin{array}{l}\text { Tabela 2: Participação dos Itens no } \\
\text { CPV } \\
\text { (Média Jan a Set/2018) }\end{array}$ \\
\hline Resina 00343527 & $18 \%$ \\
Resina 00357663 & $6 \%$ \\
Resina 00133727 & $9 \%$ \\
\hline \hline \multicolumn{1}{c}{ Total } & $33 \%$
\end{tabular}

Fonte: Dados da Pesquisa (2018)

Na Tabela 3, são destacados os preços estimados para o mês de outubro tendo como base a tabela de preços de mês de setembro/2018 mais um aumento de 6\%, esperado pelo mercado. No caso da resina, os impostos que compõem os preços abaixo são ICMS (12\%) e PIS/COFINS (9,25\%), não havendo incidência de IPI, por estar suspenso nos termos do art. 29 da Lei no 10.684/2003 e art. 26 da IN RFB 948/2009. Os itens abaixo são oriundos de uma planta da empresa situada na região Sul.

Tabela 3: Preço do Mercado Nacional em Reais (Preços Est. Out/2018 por/ton)

\begin{tabular}{cc}
\hline Resina 00343527 & $9.569,64$ \\
Resina 00357663 & $10.609,88$ \\
Resina 00133727 & $9.569,64$ \\
\hline \hline
\end{tabular}

Fonte: Dados da Pesquisa (2018) 


\section{análise do impacto no custo do produto vendido}

O preço da estimação dos custos de importação desses três itens foi feito pelo supervisor de Planejamento e Controle da Produção (PCP), que participou de todas as etapas do estudo de caso. No atual cenário regulatório, a alternativa encontrada pela empresa para fugir das barreiras protecionistas impostas pela Camex foi encontrar um fornecedor dentro do próprio Mercosul, que atendesse os padrões de qualidade exigidos pelas montadoras. Após um processo de prospecção, foi encontrado um fornecedor na Colômbia, que atendia os padrões necessários e o deadline da empresa.

A estimação foi realizada nos primeiros dias do mês de setembro de 2018 . O dólar estimado para outubro no momento do registro das importações foi de $\mathrm{R} \$ 3,88$. Para o estudo, foi considerada uma média de aumento de $6 \%$ no custo da matéria-prima local. O valor negociado por tonelada da mercadoria foi de $\$ 1.600,00$, sendo o mesmo preço praticado para todos os três itens. Adotou-se o incoterm CFR (cost and freight). A média das despesas de importação foi informada por uma empresa de trading, prestadora de serviços à empresa em estudo. Por ser a primeira importação o fornecedor exigiu pagamento antecipado, mas deixou aberta a possibilidade de negociação de um prazo de pagamento entre 30 e 60 dias para importações futuras, dependendo do volume ou de um possível contrato de fornecimento. A empresa optou pela importação por encomenda, com a intermediação da empresa de trading situada no sul do Brasil. As comparações indicaram que isso geraria uma redução nos custos, além de reduzir o desembolso com ICMS. A Tabela 4 registra os valores estimados pela empresa.

\begin{tabular}{|c|c|}
\hline Descrição & Valor \\
\hline Mercadoria CFR/R \$ & $6.208,00$ \\
\hline II - 0\% & 0,00 \\
\hline IPI - 5\% & 310,40 \\
\hline PIS - $2,1 \%$ & 130,37 \\
\hline COFINS $-9,65 \%$ & 599,07 \\
\hline ICMS - 4\% & 248,32 \\
\hline Preço com impostos & $7.496,16$ \\
\hline Despesas Imp. - 15\% & $1.124,42$ \\
\hline Preço Final & $8.620,58$ \\
\hline
\end{tabular}


O "preço net" é um termo muito utilizado no cotidiano das empresas. Ele é derivado do inglês e significa preço líquido, ou seja, sem a inclusão de qualquer imposto. Usando tal referência no mercado local, considera-se que na projeção feita para outubro existe um aumento de $6 \%$ em relação ao preço vigente em setembro. $\mathrm{O}$ “preço net” estimado para a importação da mercadoria era de R \$7.122,24. Já o preço nacional foi de $\mathrm{R} \$ 7.536,09$ para as resinas 00343527 e 00133727 e de $\mathrm{R} \$ 8.355,28$ para a resina 00357663 .

\begin{tabular}{|c|c|c|c|}
\hline Item & P. Nacional & P. Importação & Variação \\
\hline R-00343527 & $7.536,09$ & $7.122,24$ & $5,81 \%$ \\
\hline R-00357663 & $8.355,28$ & $7.122,24$ & $17,31 \%$ \\
\hline R-00133727 & $7.536,09$ & $7.122,24$ & $5,81 \%$ \\
\hline
\end{tabular}

Fonte: Dados da Pesquisa (2018)

Conforme Tabela 5, comparando o preço final líquido estimado para a importação com os preços projetados para outubro, considerando os itens em análise. A importação seria vantajosa e tal modalidade geraria um percentual de economia muito expressivo em relação à mercadoria oriunda do mercado nacional. Essa seria a primeira importação de polipropileno realizada pela empresa, desde que o grupo brasileiro assumiu o controle da mesma.

\subsection{Custos de efetivos de importação e análise do efeito da operação}

Pelo Anexo I é possível conhecer, de forma detalhada os custos efetivos que a empresa incorreu na operação de importação. A taxa de fechamento do câmbio antecipado foi de R \$ 4,1292. A importação sofreu um split - a carga sofreu uma divisão e os containers serão transportados em diferentes navios - e a quantidade total negociada de cerca de 500 toneladas foi embarcada em viagens diferentes, o que causou oscilação na taxa de registro da mercadoria e variação cambial ativa para uma das compras analisada, e passiva para as outras duas.

Quando da variação cambial ativa, acima de $\mathrm{R} \$ 4,1292$, a empresa registrou ganho com uma oscilação na cotação acima da taxa de fechamento do pagamento 
Estimação dos custos de importação para uma empresa do ramo de plásticos:

análise do impacto no custo do produto vendido

antecipado. Na variação passiva, a empresa registrou perda, devido a uma oscilação na cotação para baixo. A forma de remoção da carga também não foi a mesma para todos os casos, tendo havido desova do container em um deles e crossdocking - prática onde o container é armazenado e descarregado diretamente na transportadora que fará o transporte. Todas essas variáveis fizeram com que apesar do preço CFR ser o mesmo para todos os itens, o preço final de importação seja diferente. A quantidade embarcada em cada container foi de 25,5 toneladas. A tabela de preços efetiva divulgada para outubro no mercado nacional é expressa na Tabela 6.

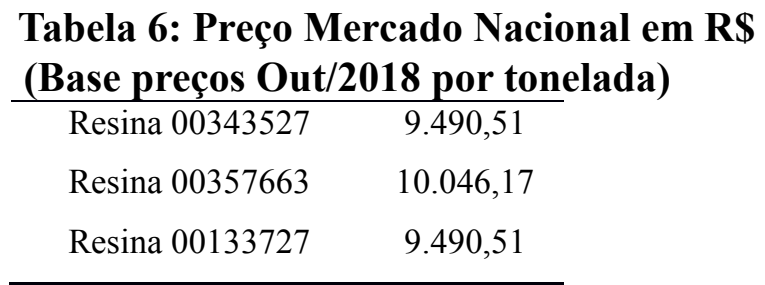

Fonte: Dados da Pesquisa (2018)

Na Tabela 7 apresenta-se de forma resumida o resultado das importações. Nele, consta o custo total da importação de cada produto, a quantidade importada e o custo por tonelada. O custo por tonelada é o que será utilizado para fins de comparação com compra no mercado nacional.

Tabela 7: Custo total e por tonelada

\begin{tabular}{cccc}
\hline Item & Custo Total & Quant. (Ton) & Custo/Ton \\
\hline R-00343527 & $218.166,81$ & 25,5 & $8.555,56$ \\
R-00357663 & $216.339,75$ & 25,5 & $8.483,91$ \\
R-00133727 & $215.494,24$ & 25,5 & $8.450,75$
\end{tabular}

Fonte: Dados da Pesquisa (2018)

$\mathrm{Na}$ análise é excluído o custo por tonelada, tanto dos itens importados quanto dos itens nacionais entre os quais figuram os impostos recuperáveis: ICMS, IPI, PIS e COFINS. Na Tabela 8 é possível verificar a variação de preço entre a compra no mercado nacional e a importação. 
Tabela 8: Comparação custo importação $x$ custo nacional

\begin{tabular}{lrrc}
\hline Item & P. Nacional & P. Importação & Variação \\
\hline R-00343527 & $7.469,13$ & $7.064,45$ & $5,73 \%$ \\
R-00357663 & $7.906,34$ & $7.005,29$ & $12,86 \%$ \\
R-00133727 & $7.469,13$ & $6.977,91$ & $7,04 \%$
\end{tabular}

Fonte: Dados da Pesquisa (2018)

Pelas análises apresentadas a partir dos casos considerados, a importação se mostrou vantajosa. Um dos aspectos relevantes, foi o fato de os itens referentes a resina terem sido importados do Mercosul, o que evita: a taxação do imposto de importação, a taxa AFRMM (sigla que significa Adicional ao Frete para Renovação da Marinha Mercante) e as possíveis tarifas antidumping. Caso não houvesse essas isenções, a importação seria provavelmente desvantajosa devido ao custo com variação cambial passiva que é expressivo em alguns dos itens, em função da oscilação do dólar no momento do registro, em comparação ao dólar de fechamento do câmbio antecipado. O fato de o mercado nacional de resina ser um monopólio contribuiu para que os preços no mercado interno sejam muitos superiores ao mercado externo, já que sem concorrentes e com barreiras de proteção impostas pelo governo para importação dos principais mercados mundiais, a empresa fornecedora fica livre para impor o preço, sendo a curva de demanda pouco sensível.

Na Tabela 9 é possível observar o impacto no CPV, pela multiplicação do percentual de redução sobre o percentual de participação do item no CPV. De janeiro até o mês de setembro/2018 toda a compra de resina foi feita no mercado nacional. O primeiro lote de produtos importados apenas entrou em consumo no final do mês de outubro.

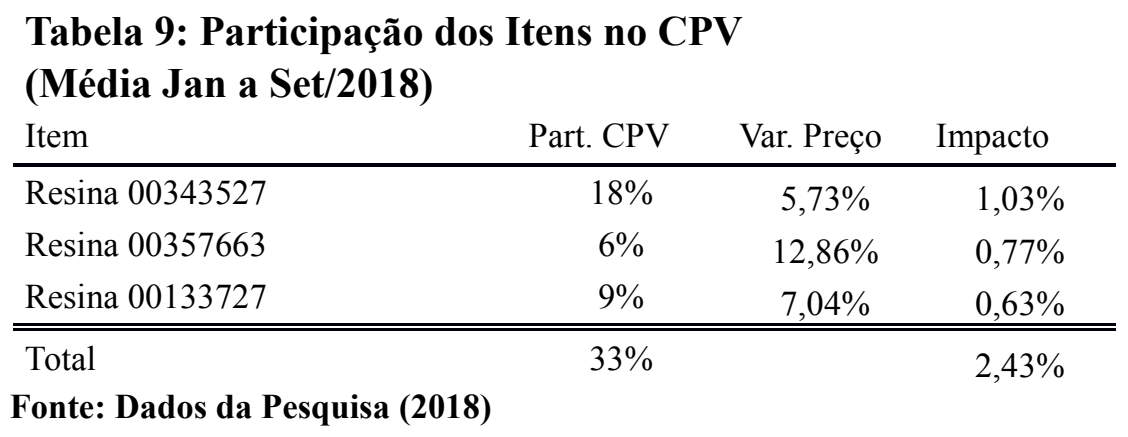

Pela análise da Tabela 9, observa-se que os três itens analisados representam $33 \%$ do total do Custo do Produto Vendido, a importação geraria uma economia em 
termos financeiros de 2,43\% considerando o CPV médio no período de janeiro a setembro de 2018. Quanto ao impacto no ciclo financeiro da empresa, infelizmente não será possível realizar a análise já que a importação teve de ser paga antecipadamente. Seria necessário esperar uma negociação com o fornecedor para determinar qual seria o prazo concedido para pagamento, e com isso analisar o efeito na redução do ciclo financeiro da empresa.

Para o estudo de caso dessa empresa em questão, a importação da matéria-prima base se mostrou vantajosa para a empresa, por gerar redução dos custos. Mesmo com as variações cambiais, o impacto não é tão significativo uma vez que os preços no mercado nacional estão ancorados aos preços do mercado internacional pela variação do dólar. Por este feito, as variações bruscas na taxa de câmbio também provocam variações bruscas no preço dos itens no mercado nacional, pelo analisado via dados históricos.

\section{CONCLUSÃO}

Ao descrever a realidade vivida pela indústria do setor de compostos plásticos para o ramo automobilístico, foi possível identificar a importância da análise de custos para a tomada de decisão, levando-se em consideração a escolha de fornecedores internacionais. O objetivo do trabalho consistiu em comparar a variação do Custo do Produto Vendido (CPV) que a importação pode gerar, em relação aos custos e a gestão do capital de giro em relação à compra nacional. Tendo em vista a estrutura de mercado nacional e as políticas de negociação com os fornecedores e os clientes, comparada às condições ofertadas para a comercialização no Mercosul, a importação foi considerada vantajosa por aumentar a margem de lucro e reduzir a necessidade de capital de giro à indústria paulista de compostos plásticos, principalmente para injeção na indústria automotiva.

Para tanto, foram evidenciadas as características do mercado desse polímero, e identificada ausência de livre concorrência. Como alternativa para fugir dos preços de monopólio o estudo demonstrou a operação de importação do produto, desde seu planejamento até a análise da operação em termos de ganho em comparação a uma operação de compra no mercado local. Desta maneira, a análise não se restringe apenas a variáveis internas, uma vez que a metodologia buscou mostrar também como as decisões da política econômica do governo impactam as empresas. Tal situação direciona as empresas a constante adaptação para a busca da sobrevivência, haja vista 
que a economia do país é afetada pelas decisões, às vezes, não razoáveis dos órgãos reguladores. Pela descrição da evolução do mercado foi possível constatar a concentração - ponto de monopólio. Tal mercado, no início dos anos 2000 apresentava certo grau de concorrência, mas devido a inúmeras operações econômicas que ocorreram, a resultante foi o seu fechamento por completo.

No tópico onde se discutiu o mercado de polipropileno no Brasil, sua evolução e concentração ao ponto de se tornar um monopólio, foi possível arrazoar pela análise dos resultados, que na economia, o mercado sempre encontra uma forma de se dinamizar. Um controle efetivo de custos e um sistema de estimativa confiável para viabilidade de importação não é algo simples de se implementar na cultura de uma empresa. O processo contemplado no estudo de caso se mostrou complexo, principalmente por envolver a variável dólar, que está atrelada a variação cambial. É ela, no final, quem determinará se a operação foi vantajosa ou não, e por isso é fundamental criar mecanismo para estabelecer uma faixa de variação que dê uma margem de segurança para a empresa prosseguir com a estimação e posterior execução da importação, via planejamento financeiro.

A metodologia contemplou a abordagem descritiva com análise qualitativa. A escolha metodológica permitiu criar um contexto que justificasse a necessidade da importação, as etapas de estimação dos custos, a efetivação da importação e a comparação da operação com o mercado externo versus o mercado interno, visando a redução de custos. Ao final de todas as etapas de compilação dos dados e comparações pode-se concluir que é vantajoso importar. A redução obtida foi superior a $2 \%$ do $\mathrm{CPV}$, mesmo com práticas logísticas a serem aprimoradas. A substituição de algumas matérias-primas, antes adquiridas no mercado nacional, por itens similares importados foi um resultado muito significativo dado às incertezas que envolvem a operação, caracterizada principalmente pela oscilação da moeda. O fornecedor estrangeiro encontrado conseguiu obter competitividade frente ao fornecedor nacional, mesmo com uma variação de $6 \%$ na cotação da moeda, em relação ao câmbio estimado.

Com o desenvolvimento da pesquisa foi possível identificar como a estimação dos custos de importação pode gerar uma economia para empresa. Apesar de a estrutura organizacional ser restrita, e distinta dos casos já analisados pela linha pesquisa em importação, as características profissionais assim como a condução do processo em si não destoam dos estudos anteriores, seguindo os passos que envolvem o processo de estimação e decisão. No caso analisado pelo presente estudo, a importação se mostrou 
Estimação dos custos de importação para uma empresa do ramo de plásticos:

análise do impacto no custo do produto vendido

como solução para a redução de custos e para a necessidade do capital de giro. Pela análise, se feita de maneira completa, abrangendo a gama de custos e as despesas envolvidas, considerando as variáveis que afetam a importação, o processo poderá ser aprimorado e a compra internacional pode ser disseminada como uma nova tática para a sustentabilidade da operação, apesar da variação cambial.

As informações coletadas demonstraram como o monopólio, a instabilidade da moeda e as barreiras alfandegárias são variáveis significativas, mas ainda assim não impeditivas de tornar a importação uma estratégia válida para redução dos custos com matéria-prima. Uma redução significativa para o componente de produção que representa $60 \%$ dos custos industriais. Ademais, deve-se considerar que os prazos adotados no mercado internacional foram salutares a prática adotada sendo, portanto, uma ação recomendada como adequada para a sobrevivência o crescimento da indústria, diante do aumento de sua competitividade.

Mesmo diante dos limites impostos pela ausência de generalização, caracterizada pela base metodológica adotada, observa-se que o instrumento de Oliveira e Ribeiro (2008) favoreceu a coleta de dados e a compreensão dos motivos considerados para a importação. Além disso, os estudos de Amaral et al (2019), Franco et al (2019), Ben e Aimi (2017) e Oliveira et al (2008 a/b) favoreceram a leitura assertiva dos dados e a compreensão do processo de importação, permitindo avançar na proposição da discussão sobre a estrutura de mercado e a necessidade de capital de giro. Tendo em vista a experiência de pesquisa, para futuros estudos seria possível criar modelos de estimação de custos de importação que alinhem a estratégia à análise dos dados, de simples manuseio, para favorecer a tomada de decisão. Recomenda-se o desenvolvimento de um modelo de estimação de custos, que aborde a variação cambial, voltada para o mercado de importação. Desta maneira, as empresas poderão alimentá-lo com variáveis presentes e futuras, considerando o horizonte de tempo para a concretização da importação, a fim de obter uma cotação que possa ter uma margem de segurança razoável, diante da análise de sensibilidade. 


\section{REFERENCIAS}

\section{AGENCIA BRASIL. Brasil entra com recurso na OMC contra decisão sobre} subsídios à indústria. Disponível em:

<http://agenciabrasil.ebc.com.br/economia/noticia/2017-09/brasil-entra-com-recursona-omc-contra-decisao-sobre-subsidios-industria>. Acesso em: 09 de fev. 2020.

AMARAL, A. A. M. ; PAULINO, B. H. F. ; VERDILE, R. J. ; REIS, W. D. ; OLIVEIRA, Josmária Lima Ribeiro de . Estimação de custos logísticos para a importação: uma análise de casos múltiplos em empresas de pequeno e médio porte. In: XV EMEPRO - Encontro Mineiro de Engenharia de Produção, 2019, Viçosa/MG. XV EMEPRO - Encontro Mineiro de Engenharia de Produção, 2019.

ASSAF NETO, Alexandre; SILVA, César Augusto Tibúrcio. Administração do capital de giro. 4. ed. São Paulo: Atlas, 2011.

BALDISSERA, C.; NOVAK, R. A.; SELENKO, O.; ANDRUCHECHEN, A. P. B. Análise do ciclo operacional e financeiro: um estudo de caso em uma empresa do ramo moveleiro de São Bento do Sul - SC. XXII Congresso Brasileiro de Custos. Anais... Foz do Iguaçu, PR, Brasil, 11 a 13 de novembro de 2015.

BARRIONUEVO FILHO, Arthur; LUCINDA, Cláudio Ribeiro. Simulação dos efeitos concorrenciais da fusão Copene-Braskem. Econ. Apl., Ribeirão Preto, v. 10, n. 4, p. 503-522, Dec. 2006. Disponível em:

$<$ http://www.scielo.br/scielo.php?script=sci_arttext\&pid=S141380502006000400002\&1 ng=en\&nrm=iso>. Acesso em: 22 nov. 2018.

BEN, Fernando; AIMI, Morgana Jordani. Análise de custos no processo de importação: viabilidade de matéria-prima no mercado externo para uma indústria de plásticos da serra gaúcha. XXIV Congresso Brasileiro de Custos, Florianópolis, SC, Brasil, 15 a 17 de novembro de 2017.

BRASKEM. A Nossa História: Desafios, inovações e conquistas fazem parte da trajetória da Braskem. Disponível em <https://www.braskem.com.br/historia>. Acesso em: 11 out. 2018. 
Estimação dos custos de importação para uma empresa do ramo de plásticos:

análise do impacto no custo do produto vendido

CARVALHO, J. L. M., TOLEDO, J. C. Polipropileno: um mercado em constante evolução. Anais... XIV CBECIMAT - Congresso Brasileiro de Engenharia e

Ciência dos Materiais, São Pedro, dez. 2000.

FRANCO, D. S.; BERNARDO, M. M. M.; OLIVEIRA, J. L. R. de. Estimação de Custos de Importação da Empresa Leal Carneiro Ferramentas Eireli. In: XV Encontro Mineiro de Engenharia de Produção, 2019, Viçosa/MG. XV ENCONTRO MINEIRO DE ENGENHARIA DE PRODUÇÃO, 2019.

FURTADO, João. As relações tecnológicas do Brasil com o mundo exterior: passado, presente e perspectivas. Rev. USP, São Paulo, n. 89, maio 2011. Disponível em $<$ http://rusp.scielo.br/scielo.php?script=sci_arttext\&pid=S010399892011000200015\&ln $\mathrm{g}=\mathrm{pt \& nrm=iso>}$. Acesso em: 18 out. 2018.

OLIVEIRA, J. L. R. de; PACHECO, G. de; OLIVEIRA, S. L. de. Análise dos fatores que influenciam o processo de estimação de custos de importação em um laboratório veterinário. Anais... XIII Congresso Brasileiro de Custos. CBC: Belo Horizonte/MG, 2006.

OLIVEIRA, J. L. R. de; SOUZA, A. A. de; OLIVEIRA, S. L. de. Estimativa de Custos de Importação da Loja Elétrica. Revista Contemporânea de Contabilidade (Florianópolis), v. 1, p. 47-72, 2005.

OLIVEIRA, J. L. R. de; SOUZA, A. A. Estimação de custos para a importação. In: Congresso Brasileiro de Custos. Anais eletrônicos... Porto Seguro/BA: ABCustos, 2004.

OLIVEIRA, Josmária L. R. de; SOUZA, Antônio Artur de; RIBEIRO, Karla Lorena Bessa; OLIVEIRA, Sidney Lino de. Análise do processo de estimação de custos para a importação em uma empresa de materiais refratários. Revista Universo Contábil, [S.1.], v. 4, n. 4, p. 77-96, nov. 2008a. ISSN 1809-3337. Disponível em: $<$ http://proxy.furb.br/ojs/index.php/universocontabil/article/view/1061>. Acessado em: 17 maio de 2019. 
OLIVEIRA, Josmária Lima Ribeiro de; RIBEIRO, K. L. B. Componentes fundamentais para a estimação de custos na importação. In: Congresso Brasileiro de Custos, 2008, Curitiba. XV Congresso Brasileiro de Custos, 2008.

OLIVEIRA, Josmária Lima Ribeiro de; SOUZA, Antonio Artur de ; RIBEIRO, K. L. B. . Gestão de compras internacionais da Gerdau - Açominas. In: V Simpósio de Gestão e Estratégia em Negócios da UFRuralRJ, 2007, Seropédica. V Simpósio de Gestão e Estratégia em Negócios da UFRuralRJ. Seropédica: UFRRJ, 2007.

OLIVEIRA, Josmária Lima Ribeiro de; SOUZA, Antonio Artur de ; FREITAS, A. G. R. ; RIBEIRO, K. L. B. . Gestão de informações de custos para a atividade de importação em uma indústria automobilística. REGE. Revista de Gestão USP, v. 15, p. 15-28, 2008b.

PADOVEZE, Clóvis Luís; BENEDICTO, Gideon Carvalho de. Análise das

Demonstrações Financeiras. 3. ed. rev. e ampl. São Paulo: Cengage Learning, 2010.

PETRY, André. Mercado brasileiro de polipropileno com ênfase no setor automobilístico. Trabalho de Conclusão de Curso. Universidade Federal do Rio Grande do Sul, 2011. Disponível em: <https://lume.ufrgs.br/handle/10183/36895>. Acesso em 6 de outubro de 2018.

PLASTICS INSIGHTS. 2016. Global Production of Prolypropylene. All About Polypropylene (PP): Production, Price, Market \& its Properties. Disponível em <https://www.plasticsinsight.com/resin-intelligence/resin-prices/polypropylene/>. Acesso em 5 de outubro de 2018.

INVESTEXPORTBRASIL. O mercado brasileiro para o prolipropileno originário da Colômbia. Disponível em:

<http://www.investexportbrasil.gov.br/sites/default/files/publicacoes/PSCI/PSCIColom biaPolipropileno.pdf>. Acesso em 2 out. 2018.

SOARES, Pedro; ARAUJO, Paulo de. Braskem leva Quattor com R\$ 2,5 bi de estatal. FOLHA DE SÃO PAULO, 23 de janeiro de 2010. São Paulo: Grupo Folha, [1921]-. Diário. Disponível em: < 
Estimação dos custos de importação para uma empresa do ramo de plásticos: análise do impacto no custo do produto vendido

https://www1.folha.uol.com.br/fsp/dinheiro/fi2301201009.htm >. Acesso em: 10 out. 2018.

SOUZA, Antonio Artur de; OLIVEIRA, Josmária Lima Ribeiro de; RIBEIRO, K. L. B.. Processo de importação em uma indústria automobilística. ABCustos (São Leopoldo, RS),v. III, p. 21-44, 2008. 
Bruno Henrique Ferreira de Paulino, Josmária Lima Ribeiro de Oliveira e

Ana Tereza Lanna Figueiredo

ANEXO I

\begin{tabular}{|c|c|c|c|c|c|c|c|c|}
\hline \multicolumn{3}{|c|}{ ITEM ==> } & \multicolumn{2}{|r|}{ R-00343527 } & \multicolumn{2}{|c|}{ R-00357663 } & \multicolumn{2}{|c|}{ R-00133727 } \\
\hline \multicolumn{3}{|c|}{ TAXA DOLAR REGISTRO } & & 3,8542 & & 4,0594 & & 4,0039 \\
\hline \multicolumn{9}{|c|}{ V ALOR DA MERCADORIA } \\
\hline F.O.B. & & & $R \$$ & $153.040,65$ & $\mathrm{R} \$ 1$ & $162.741,35$ & $\mathrm{R} \$ 1$ & $160.516,35$ \\
\hline FRETE & & & $\mathrm{R} \$$ & $2.736,48$ & $\mathrm{R} \$$ & $2.882,18$ & $R \$$ & $2.842,77$ \\
\hline SEGURO & & & $\mathrm{R} \$$ & 365,00 & $\mathrm{R} \$$ & 387,86 & $R \$$ & 382,56 \\
\hline \multicolumn{3}{|l|}{ CIF } & $R \$$ & $156.142,13$ & $\mathrm{R} \$ 1$ & $166.011,38$ & $R \$ 1$ & $163.741,68$ \\
\hline \multicolumn{9}{|c|}{ IMPOSTOS DE NACIONALIZAÇÃO } \\
\hline COFINS & & & $R \$$ & $15.139,13$ & $\mathrm{R} \$$ & $16.020,10$ & $\mathrm{R} \$$ & $15.801,07$ \\
\hline I.P.I & & & $R \$$ & $7.844,11$ & $R \$$ & $8.300,57$ & $R \$$ & $8.187,09$ \\
\hline PIS & & & $R \$$ & $3.294,53$ & $\mathrm{R} \$$ & $3.486,24$ & $R \$$ & $3.438,58$ \\
\hline I.I. & & & & - & & - & & - \\
\hline \multicolumn{3}{|c|}{ TOTAL DOS IMPOSTOS } & $\mathrm{R} \$$ & $26.277,76$ & $\mathrm{R} \$$ & $27.806,91$ & $R \$$ & $27.426,73$ \\
\hline \multicolumn{9}{|c|}{ DESPESAS OPERACIONAIS } \\
\hline \multicolumn{3}{|c|}{ 401-CORRETAGEM DE CAMBIO } & $R \$$ & 57,81 & $R \$$ & 60,89 & $R \$$ & 60,06 \\
\hline \multicolumn{3}{|c|}{ 402-ARMAZENAGEM PORTUARIA } & $\mathrm{R} \$$ & $3.027,82$ & $R \$$ & $2.908,14$ & $\mathrm{R} \$$ & $2.849,72$ \\
\hline \multicolumn{3}{|c|}{ 404-DESPACHANTE SERVICOS } & $R \$$ & $1.050,00$ & $R \$$ & $1.050,00$ & $R \$$ & $1.050,00$ \\
\hline \multicolumn{3}{|c|}{ 406-TRANSPORTE INTERNO } & $R \$$ & $5.532,01$ & $R \$$ & $5.410,62$ & $R \$$ & $5.528,97$ \\
\hline \multicolumn{3}{|c|}{ 416-VARIACAO CAMBIAL } & & $11.114,82$ & & $(322,32)$ & $R \$$ & $1.942,08$ \\
\hline \multicolumn{3}{|c|}{ 417-Taxa LI - Orgao Anuente } & $R \$$ & 88,17 & $\mathrm{R} \$$ & 88,17 & $R \$$ & 88,17 \\
\hline 428-ISPS & & & $R \$$ & 56,00 & $R \$$ & 78,00 & $R \$$ & 78,00 \\
\hline 436-LEVA & E DE CNTR- & RTO OU EA & $R \$$ & 490,00 & $R \$$ & 490,00 & $R \$$ & 490,00 \\
\hline 438-POSIC & NAMENTO & STORIA & $R \$$ & 330,00 & $\mathrm{R} \$$ & 330,00 & & - \\
\hline 444-DESO & A DE CONTA & & & - & $R \$$ & 415,00 & & - \\
\hline 457-TX AD & INISTRA TIV & TERCEIROS & $R \$$ & 200,00 & $R \$$ & 200,00 & $R \$$ & 200,00 \\
\hline 465-Taxa I & ntagem LI & & $R \$$ & 50,00 & $\mathrm{R} \$$ & 50,00 & $R \$$ & 50,00 \\
\hline 467-TRAN & 3ORDOICRO & SDOCKING & $R \$$ & $1.680,00$ & & - & $R \$$ & $1.350,00$ \\
\hline 503-TAXA & ISCOMEX & & $R \$$ & 214,50 & $R \$$ & 214,50 & $R \$$ & 214,50 \\
\hline 505-REMO & AO INTRAMU & ICIPAL & & - & $\mathrm{R} \$$ & $1.290,14$ & $R \$$ & $1.284,74$ \\
\hline 508-LIBER & $\mathrm{SAO} B / \mathrm{LOU}$ & WB & $R \$$ & 406,00 & $R \$$ & 403,00 & $R \$$ & 403,00 \\
\hline 509-ARMA & ENAGEM EA & & & - & $R \$$ & $1.062,47$ & $R \$$ & 400,00 \\
\hline 514-AD V & OREM & 0,10588 & $R \$$ & 460,85 & $\mathrm{R} \$$ & 456,99 & $\mathrm{R} \$$ & 455,21 \\
\hline 526-DEVO & JCAO CNTR & $A Z I O$ & & - & $R \$$ & 377,40 & & - \\
\hline 528-MOV II & $\mathrm{NTACAO} / \mathrm{H}$ & IDLING CNTP & & - & $R \$$ & 655,00 & $R \$$ & 360,00 \\
\hline 530-SEGU & EADI & & & - & $\mathrm{R} \$$ & 166,01 & $R \$$ & 163,74 \\
\hline 518-PESA & & & $R \$$ & 170,00 & & - & & - \\
\hline $546-\mathrm{THC} / \mathrm{C}$ & PATAZIAS - & ASE IMPOST & $R \$$ & 740,00 & & - & & - \\
\hline 547-DIREIT & S ANTIDUMF & & & - & & - & & - \\
\hline 548-AFRR & & & & - & & - & & - \\
\hline TOTAL DE & PESAS OPE & ACIONAIS & $R \$$ & $25.667,98$ & $\mathrm{R} \$$ & $15.384,01$ & $R$ \$ & $16.968,19$ \\
\hline DESPESAS & INANCERA & & & & & & & \\
\hline 418-DESPE & AS FINANCE & AS & $R \$$ & $3.659,87$ & $\mathrm{R} \$$ & $3.904,83$ & $R \$$ & $3.532,35$ \\
\hline 472-ABAT & ENTO & & & $(2.285,56)$ & & $(2.266,42)$ & & $(2.257,56)$ \\
\hline TOTAL DE & PESAS FINA & CERAS & $\mathrm{R} \$$ & $1.374,32$ & $\mathrm{R} \$$ & $1.638,41$ & $R \$$ & $1.274,79$ \\
\hline COMPOSI & ÃO DA N & DA & & & & & & \\
\hline CUSTO TO & & & $R \$$ & $206.525,10$ & $\mathrm{R} \$ 2$ & $206.544,75$ & $R \$ 2$ & $205.466,02$ \\
\hline CREDTO D & COFINS & & & $(15.139,13)$ & & $(16.020,10)$ & & $(15.801,07)$ \\
\hline CREDITO D & I.P.I. & & & $(7.844,11)$ & & $(8.300,57)$ & & $(8.187,09)$ \\
\hline CREDITO D & PIS & & & $(3.294,53)$ & & $(3.486,24)$ & & $(3.438,58)$ \\
\hline CUSTO Al & ES DOS IM & STOS & $R$ & $360.494,68$ & $\mathrm{R} \$ 3$ & $357.475,67$ & $R \$ 3$ & $356.078,57$ \\
\hline COFINS & & 0,076 & $R \$$ & $15.791,12$ & $\mathrm{R} \$$ & $15.658,88$ & $R \$$ & $15.597,68$ \\
\hline ICMS & & 0,04 & $R \$$ & $8.311,12$ & $R \$$ & $8.241,52$ & $R \$$ & $8.209,31$ \\
\hline PIS & & 0,0165 & $\mathrm{R} \$$ & $3.428,34$ & $\mathrm{R} \$$ & $3.399,63$ & $\mathrm{R} \$$ & $3.386,34$ \\
\hline TOTAL NF & / IPI & & & $207.777,91$ & $\mathrm{R} \$ 2$ & $206.037,85$ & $R \$ 2$ & $205.232,61$ \\
\hline I.P.I. & & & & $10.388,90$ & & $10.301,90$ & & $10.261,63$ \\
\hline TOTAL NF & C/IPI) & & & $218.166,81$ & $\mathrm{R} \$ 2$ & $216.339,75$ & $R \$ 2$ & $215.494,24$ \\
\hline VALOR UI & IÁRIO/TON & & $\mathrm{R} \$$ & $8.555,56$ & $\mathbf{R} \$$ & $8.483,91$ & $R \$$ & $8.450,75$ \\
\hline
\end{tabular}

